\title{
Controls on the Activation and Strength of a High-Latitude Convective Cloud Feedback
}

\author{
DORIAN S. ABBOT \\ School of Engineering and Applied Sciences, Harvard University, Cambridge, Massachusetts \\ ELI TZIPERMAN \\ School of Engineering and Applied Sciences, and Department of Earth and Planetary Science, Harvard University, Cambridge, \\ Massachusetts
}

(Manuscript received 23 May 2008, in final form 31 July 2008)

\begin{abstract}
Previous work has shown that a convective cloud feedback can greatly increase high-latitude surface temperature upon the removal of sea ice and can keep sea ice from forming throughout polar night. This feedback activates at increased greenhouse gas concentrations. It may help to explain the warm "equable climates" of the late Cretaceous and early Paleogene eras ( $\sim 100$ to $\sim 35$ million years ago) and may be relevant for future climate under global warming. Here, the factors that determine the critical threshold $\mathrm{CO}_{2}$ concentration at which this feedback is active and the magnitude of the warming caused by the feedback are analyzed using both a highly idealized model and NCAR's single-column atmospheric model (SCAM) run under Arctic-like conditions. The critical $\mathrm{CO}_{2}$ is particularly important because it helps to establish the relevance of the feedback for past and future climates.

Both models agree that increased heat flux into the high latitudes at low altitudes generally decreases the critical $\mathrm{CO}_{2}$. Increases in oceanic heat transport and in solar radiation absorbed during the summer should cause a sharp decrease in the critical $\mathrm{CO}_{2}$, but the effect of increases in atmospheric heat transport depends on its vertical distribution. It is furthermore found (i) that if the onset of convection produces more clouds and moisture, the critical $\mathrm{CO}_{2}$ should decrease, and the maximum temperature increase caused by the convective cloud feedback should increase and (ii) that reducing the depth of convection reduces the critical $\mathrm{CO}_{2}$ but has little effect on the maximum temperature increase caused by the convective cloud feedback. These results should help with interpretation of the strength and onset of the convective cloud feedback as found, for example, in Intergovernmental Panel on Climate Change (IPCC) coupled ocean-atmosphere models with different cloud and convection schemes.
\end{abstract}

\section{Introduction}

Cloud feedbacks represent the most important source of uncertainty in the climate system (Cess et al. 1990, 1996; Baker 1997; Murphy et al. 2004; Stainforth et al. 2005; Soden and Held 2006). This motivates the idea that cloud feedbacks might play an important role in explaining past "equable climates" and makes understanding clouds important for understanding future climate under increased greenhouse gas levels. Equable climates, which prevailed during the late Cretaceous and early Paleogene ( $\sim 100$ to $\sim 35$ million years ago), were characterized by warm high latitudes (e.g., Zachos

Corresponding author address: Dorian Abbot, Harvard University, 24 Oxford St., Cambridge, MA 02138.

E-mail: abbot@fas.harvard.edu et al. 2001; Sluijs et al. 2006), particularly during the winter and over continents (e.g., Greenwood and Wing 1995), and tropical temperatures only somewhat higher than modern (e.g., Pearson et al. 2001; Norris et al. 2002; Roche et al. 2006; Tripati et al. 2003). Various mechanisms have been proposed to explain either the relatively cool tropical temperatures or relatively warm polar temperatures, including increased ocean heat transport due to ocean mixing by increased hurricane activity (Emanuel 2002; Korty et al. 2008), the Hadley cell extending nearly to the pole (Farrell 1990), and high-latitude longwave heating due to thick polar stratospheric clouds (Sloan et al. 1992; Sloan and Pollard 1998; Peters and Sloan 2000; Kirk-Davidoff et al. 2002).

Abbot and Tziperman (2008a) proposed a positive feedback on high-latitude temperatures that results 
from the onset of convective clouds. A related suggestion was also briefly made by Sloan et al. (1999) and Huber and Sloan (1999). In this proposed feedback, an initial warming leads to destabilization of the highlatitude atmosphere to convection, causing convection, which results in convective clouds and increased atmospheric moisture, both of which trap outgoing longwave radiation and lead to further warming.

Over ocean, this feedback should occur preferentially during winter (Abbot and Tziperman 2008b, hereafter AT08b; Abbot et al. 2008, manuscript submitted to $J$. Climate, hereafter AWT) because during summer marine boundary layer clouds block low-level atmospheric solar absorption, so that solar absorption occurs preferentially in the midtroposphere and stabilizes the lower atmosphere.

The convective cloud feedback as outlined in AT08b and AWT is intimately tied to sea ice, which insulates the ocean and prevents convection when it is present, whereas the feedback prevents the formation of sea ice when there is none (AT08b; AWT). Abbot and Tziperman (2008a), however, found that the convective cloud feedback can operate based on atmospheric processes alone. This distinction is important because it underscores the possibility that the convective cloud feedback could lead to further warming even after the complete removal of sea ice, and we will return to it in the discussion (section 4).

The convective cloud feedback allows for multiple equilibria: one solution that is convecting and is warm and another solution that is not convecting and is cold. The purpose of this paper is to determine what parameters control the lowest (critical) $\mathrm{CO}_{2}$ value at which the warm state can exist and the temperature difference between the two states. The critical $\mathrm{CO}_{2}$ is important because it determines whether the convective cloud feedback could have been active during periods of equable climate and whether it could be active in a future climate under global warming. The temperature difference between the two states is important because it represents the strength of the convective cloud feedback.

In section 2 we develop a simple two-level atmosphere-surface model that encapsulates the most basic physics that can describe the atmosphere-only convective cloud feedback. We use this model to qualitatively determine the way in which various parameters affect the onset of the feedback and its strength. This analysis should aid interpretation of the convective cloud feedback in more complex models, such as the Intergovernmental Panel on Climate Change (IPCC) coupled GCMs, in which the convective cloud feedback has been shown to be active (AWT).
In section 3 we extend this analysis using the National Center for Atmospheric Research (NCAR) singlecolumn atmospheric model (SCAM). SCAM contains the full cloud, convection, and radiation parameterizations of the NCAR community atmosphere model (CAM), but heat transports into it and velocities acting on it must be prescribed. We show that SCAM's behavior is consistent with that of the two-level model and that the lessons from the simpler model can be used to understand the more complete SCAM.

\section{Two-level model}

\section{a. Developing the model}

In this section we construct a simple two-level model of the atmosphere in which we attempt to capture the simplest system in which the convective cloud feedback can function. Based on previous work (Abbot and Tziperman 2008a; AT08b; AWT), we expect the convective cloud feedback to be active at high latitudes (roughly poleward of $60^{\circ}$ ) during winter, and we will make assumptions accordingly throughout this section. In this model, the top level represents the free troposphere (200-900 hPa; henceforth the atmosphere) and the lower level (henceforth the surface) represents the combined boundary layer (900-1000 hPa) and surface-for example, a mixed-layer ocean (top $50 \mathrm{~m}$ ). In effect, we assume that turbulent fluxes tie the surface to the boundary layer so tightly that they behave as one. Energy balance for this model can be written as

$$
\begin{gathered}
C_{s} \frac{d T_{\mathrm{s}}}{d t}=F_{\mathrm{s}}-F_{\mathrm{c}}+\varepsilon \sigma T_{\mathrm{a}}^{4}-\sigma T_{\mathrm{s}}^{4}, \\
C_{a} \frac{d T_{\mathrm{a}}}{d t}=F_{\mathrm{a}}+F_{\mathrm{c}}+\varepsilon \sigma\left(T_{\mathrm{s}}^{4}-2 T_{\mathrm{a}}^{4}\right) .
\end{gathered}
$$

Here, $C_{s}$ and $C_{a}$ are the total heat capacities of the surface and atmospheric columns (standard heat capacity multiplied by total column mass), respectively; $T_{s}$ and $T_{a}$ are the surface and atmospheric temperatures, respectively; $F_{s}$ is the heat flux into the surface and boundary layer from solar radiation and by horizontal heat transport, which can be written $F_{s}=$ $F_{o}+S(1-\alpha)+F_{a}^{\mathrm{bl}}$ (where $F_{o}$ is the meridional ocean heat transport convergence, $S$ is the solar heat flux, $\alpha$ is the albedo, and $F_{a}^{\mathrm{bl}}$ is the atmospheric transport convergence into the boundary layer); $F_{a}$ is the meridional heat transport convergence into the atmospheric layer; $F_{c}$ is the convective heat flux from the boundary layer to the free troposphere; $\varepsilon$ is the emissivity of the free troposphere; and $\sigma$ is the Stefan-Boltzmann constant. 
The convective heat flux $F_{c}$ and the free tropospheric emissivity $\varepsilon$ depend on whether or not there is convection, which in turn depends on the moist stability. We determine moist stability by comparing the surface moist static energy $\left(M_{S}\right)$

$$
M_{s}=C_{p} T_{s}+L r_{s},
$$

with the atmospheric saturation moist static energy $\left(M_{a}^{*}\right)$

$$
M_{a}^{*}=C_{p} T_{a}+L r_{a}^{*}+g z_{a}
$$

where $C_{p}$ is the specific heat of air at constant pressure, $L$ is the latent heat of evaporation, $r_{s}$ is the surface specific humidity, $r_{a}^{*}$ is the free tropospheric saturation specific humidity, $g$ is the earth's gravitational constant, and $z_{a}$ is the height of the atmospheric layer (we specify the pressure of this layer, $P_{a}$, and calculate $z_{a}$ using a scale height of $8 \mathrm{~km}$ ). We calculate $r_{s}$ by assuming a constant boundary layer relative humidity, RH. If $M_{s}<M_{a}^{*}$, the model is stable to moist convection and there is no convection; consequently, we set the convective heat flux to zero $\left(F_{c}=0\right)$ and we set the emissivity to a background value [i.e., $\varepsilon=\varepsilon_{0}$, where $\varepsilon_{0}$ represents the free tropospheric emissivity in the absence of convection, which should be roughly linear in $\log \left(\mathrm{CO}_{2}\right)$ (Sasamori 1968)]. Otherwise, we choose $F_{c}$ to satisfy the moist stability criticality $\left(M_{s}=M_{a}^{*}\right.$; see below) and set $\varepsilon=\varepsilon_{0}+\Delta \varepsilon$.

Our use of $F_{c}$ to satisfy the moist stability criticality represents the basic physics of adjustment to a neutrally buoyant profile in a moist atmosphere. Our assumption that the atmospheric emissivity increases from a background emissivity $\left(\varepsilon_{0}\right)$ when there is no convection by some offset $(\Delta \varepsilon)$ upon the onset of convection represents the advent of radiatively thick convective clouds and the increase in high-altitude moisture; this is how the convective cloud feedback manifests itself in this model. Convective clouds could also affect the model albedo and through it $F_{s}$; however, based on previous SCAM and GCM investigations of the seasonality of the convective cloud feedback (AT08b; AWT), we will focus on high-latitude winters when the incoming solar radiation $S$ is small or zero, making such an effect irrelevant.

We can solve for the steady-state solutions of the model by setting the time tendencies of (1) and (2) to zero. First consider the nonconvecting state, in which $F_{c}=0$ and $\varepsilon=\varepsilon_{0}$. We have

$$
\begin{aligned}
& 0=F_{s}+\varepsilon_{0} \sigma T_{a 1}^{4}-\sigma T_{s 1}^{4}, \\
& 0=F_{a}+\varepsilon_{0} \sigma\left(T_{s 1}^{4}-2 T_{a 1}^{4}\right),
\end{aligned}
$$

where the subscript 1 signifies that this is the nonconvecting solution. We can solve (3) and (4) for the nonconvecting surface and atmospheric temperatures:

$$
\begin{aligned}
& T_{s 1}=\left[\frac{2 F_{s}+F_{a}}{\left(2-\varepsilon_{0}\right) \sigma}\right]^{\frac{1}{4}}, \\
& T_{a 1}=\left[\frac{\varepsilon_{0} F_{s}+F_{a}}{\left(2-\varepsilon_{0}\right) \varepsilon_{0} \sigma}\right]^{\frac{1}{4}} .
\end{aligned}
$$

This solution is valid so long as $M_{s 1} \leq M_{a 1}^{*}$.

When the model is convecting, we obtain the equations

$$
\begin{aligned}
0 & =F_{s}-F_{c}+\tilde{\varepsilon} \sigma T_{a 2}^{4}-\sigma T_{s 2}^{4}, \\
0 & =F_{a}+F_{c}+\tilde{\varepsilon} \sigma\left(T_{s 2}^{4}-2 T_{a 2}^{4}\right) \quad \text { and } \\
C_{p} T_{s 2}+L r_{s 2} & =C_{p} T_{a 2}+L r_{a 2}^{*}+g z_{a},
\end{aligned}
$$

where $\tilde{\varepsilon} \equiv \varepsilon_{0}+\Delta \varepsilon$ and the subscript 2 signifies the convecting solution. Equation (9) represents the moist convective criticality $\left(M_{s 2}=M_{a 2}^{*}\right)$. Equations (7)-(9) can be solved for $T_{s 2}, T_{a 2}$, and $F_{c}$. This solution is valid so long as $F_{c}>0$.

We plot the convecting and nonconvecting solutions of the two-level model as a function of $\varepsilon_{0}$ in Fig. 1. Here we choose $F_{a}=100 \mathrm{~W} \mathrm{~m}^{-2}$, which is a reasonable highlatitude value (Trenberth and Stepaniak 2003), and $F_{s}=$ $250 \mathrm{~W} \mathrm{~m}^{-2}$, which we take, for the most part, to represent heat absorbed and stored by the ocean during the summer and released back into the atmosphere during the winter. The simplicity of the model, with only one layer to represent the atmosphere, requires us to choose an unrealistically high $F_{s}\left(250 \mathrm{~W} \mathrm{~m}^{-2}\right)$ to obtain the convecting solution; $F_{S}$ takes much smaller values when we use the more realistic SCAM model (section 3). We take $\Delta \varepsilon=0.3$ and $P_{a}=600 \mathrm{hPa}$, representing mediumheight convection that produces optically thick clouds.

The nonconvecting solution exists at low values of the clear-sky emissivity, $\varepsilon_{0}$, but not at higher values (Fig. 1a, solid black line). The convecting solution exists at high $\varepsilon_{0}$ but disappears for $\varepsilon_{0}$ below some critical $\varepsilon_{0}$ which we call $\varepsilon_{c} ; \varepsilon_{c}$ is the two-level model analog of the logarithm of the critical $\mathrm{CO}_{2}$. Below $\varepsilon_{c}$, the two-level model is no longer warm enough to consistently sustain convection [i.e., (7)-(9) yield $F_{c}<0$ ]. Because the free tropospheric emissivity is increased by $\Delta \varepsilon$ because of the appearance of convective clouds and increased moisture in the convecting solution, the convecting solution has a higher surface temperature than the nonconvecting solution at all $\varepsilon_{0}$.

The vertical temperature profile of the convecting solution follows the moist lapse rate, whereas the lapse rate of the nonconvecting solution is determined radiatively (Fig. 1d). This causes the nonconvecting surface 

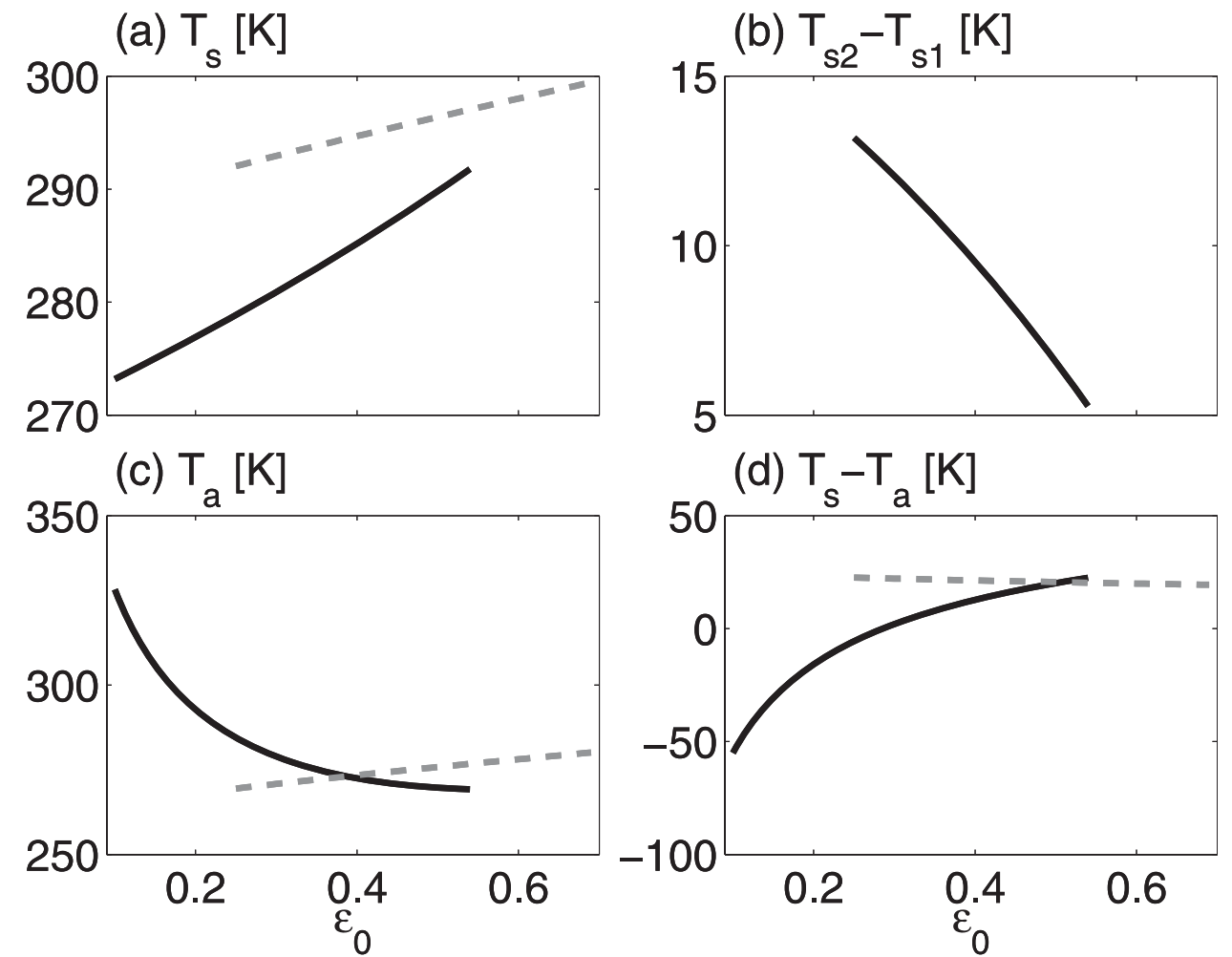

FIG. 1. Solution to the two-level model as a function of $\varepsilon_{0}$, which is a proxy for $\log \left(\mathrm{CO}_{2}\right)$ concentration. (a) Nonconvecting $\left(T_{s 1}\right.$; black solid line) and convecting $\left(T_{s 2}\right.$; gray dashed line) solution surface temperature; (b) difference between the surface temperature of the convecting and nonconvecting solutions $\left(T_{s 2}-T_{s 1}\right)$; (c) nonconvecting ( $T_{a 1}$; black solid line) and convecting ( $T_{a 2}$; gray dashed line) solution atmospheric temperature; (d) nonconvecting $\left(T_{s 1}-T_{a 1}\right.$; black solid line) and convecting $\left(T_{s 2}-T_{a 2}\right.$; gray dashed line) solution lapse rate. Model parameters are $F_{s}=250 \mathrm{~W} \mathrm{~m}^{-2}, F_{a}=100 \mathrm{~W} \mathrm{~m}^{-2}, \Delta \varepsilon=0.3$, $P_{a}=600 \mathrm{hPa}$, and $\mathrm{RH}=0.85$.

temperature to increase much faster with $\varepsilon_{0}$ than the convecting surface temperature does $\left(d T_{s 1} / d \varepsilon_{0}>d T_{s 2} /\right.$ $d \varepsilon_{0}$; Fig. 1a). Consequently, the maximum difference in surface temperature between the convecting and nonconvecting solutions as a function of $\varepsilon_{0},\left(T_{s 2}-T_{s 1}\right)_{\max }$ occurs at the minimum value of $\varepsilon_{0}$ at which convection is possible $\left(\varepsilon_{0}=\varepsilon_{c}\right)$.

There is a singularity in the nonconvecting atmospheric temperature (6) as $\varepsilon_{0}$ approaches zero if $F_{a}$, the atmospheric heat transport (AHT), is nonzero. This leads to a negative lapse rate at low $\varepsilon_{0}$ (Fig. 1d), which to some extent could be a realistic representation of a high-latitude winter inversion; however, the extreme increase of $T_{a 1}$ as $\varepsilon_{0}$ goes to zero is due to the simplicity of the model and is not realistic. In any case, this does not affect the surface temperature (5), which is the quantity in which we are primarily interested.

\section{$b$. Using the model to understand the convective cloud feedback}

We now focus on how the model parameters affect $\varepsilon_{c}$, the lowest $\varepsilon_{0}$ at which the convecting solution can exist, and $\left(T_{s 2}-T_{s 1}\right)_{\max }$, the maximum difference in surface temperature between the convecting and nonconvecting solutions as a function of $\varepsilon_{0}$. The critical value $\varepsilon_{c}$ is important for two reasons. First, because $\varepsilon_{0}$ can be thought of as roughly representing $\log \left(\mathrm{CO}_{2}\right)$ in this model, $\varepsilon_{c}$ is related to the lowest $\mathrm{CO}_{2}$ concentration at which the convecting solution can exist, which is critical to whether or not the convecting solution could be realized during an equable climate or future climate with increased greenhouse gases. Second, because $\left(T_{s 2}-T_{s 1}\right)_{\max }$ occurs at $\varepsilon_{0}=\varepsilon_{c}$ and $d T_{s 1} / d \varepsilon_{0}>d T_{s 2} / d \varepsilon_{0}$, decreasing $\varepsilon_{c}$ tends to increase $\left(T_{s 2}-T_{s 1}\right)_{\max }$, which is itself important because $\left(T_{s 2}-T_{s 1}\right)_{\max }$ represents the strength of the convective cloud feedback. Stated again, the lower the critical $\mathrm{CO}_{2}$, the larger the maximum temperature increase caused by the convective cloud feedback, all other things being equal.

In Figs. 2 and 3, we show how $\left(T_{s 2}-T_{s 1}\right)_{\max }$ and $\varepsilon_{c}$ change as we vary $\Delta \varepsilon, F_{s}, F_{a}$, and $P_{a}$, which are the important independent model parameters. Here, $\Delta \varepsilon$ represents the increase in optical thickness of the atmosphere associated with clouds and water vapor upon 
(a)

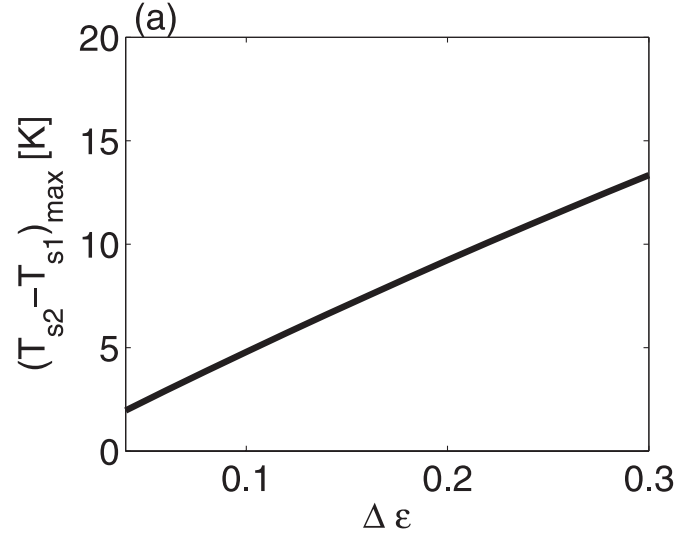

(c)

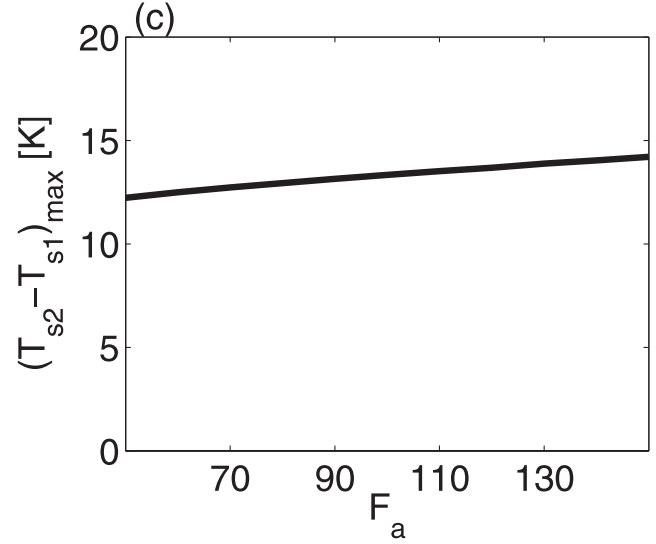

(b)

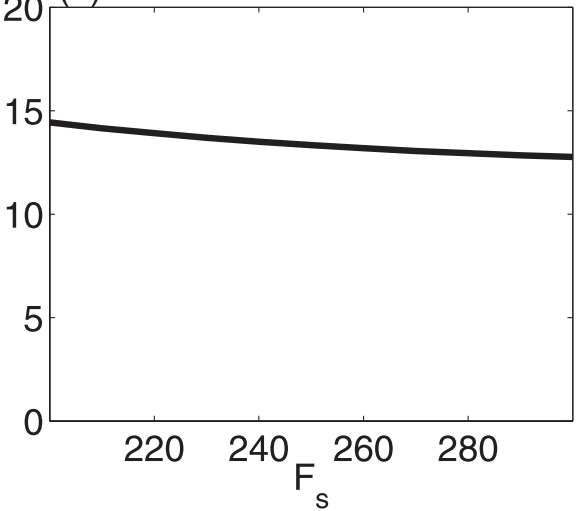

(d)

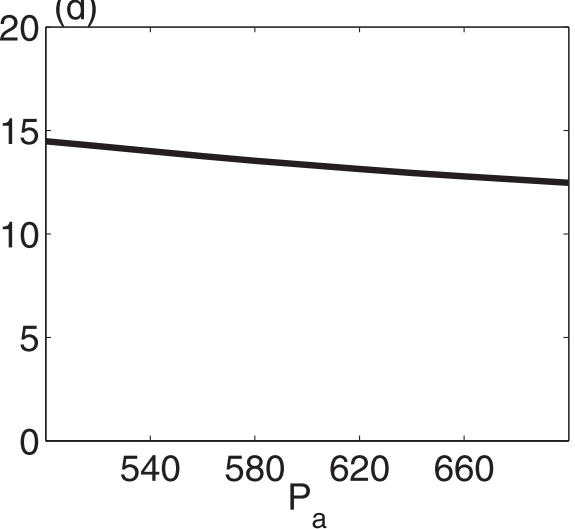

FIG. 2. Maximum difference in surface temperature between the convecting and nonconvecting solutions as a function of (a) $\Delta \varepsilon$, the increase in atmospheric emissivity resulting from the onset of convection; (b) $F_{s}$, the heat flux into the surface (which we view as mostly representing solar heat absorbed by the surface during summer and released into the atmosphere during the winter); (c) $F_{a}$, the heat flux into the atmosphere; and (d) $P_{a}$, the pressure of the atmospheric level (depth of convection). Model parameters, except for the parameter varied, are as in Fig. 1.

the onset of convection. We see $F_{s}$ as mostly representing solar heat absorbed by the surface during summer and released into the atmosphere during the winter; $F_{a}$ represents the convergence of atmospheric heat transport, and $P_{a}$ represents the depth of convection. Our main findings in this section are (i) that changing $\Delta \varepsilon$ has a significant effect on $\left(T_{s 2}-T_{s 1}\right)_{\max }$ whereas changing the other variables does not and (ii) that $\varepsilon_{c}$ tends to be more sensitive to changes in all the variables than $\left(T_{s 2}-T_{s 1}\right)_{\max }$ does.

Increasing $\Delta \varepsilon$ causes no change in the nonconvecting solution. Increasing $\Delta \varepsilon$ warms the convecting solution, which itself increases $\left(T_{s 2}-T_{s 1}\right)_{\max }$, but it also allows the convecting solution to exist at lower $\varepsilon_{0}$ (Fig. 3a), which, as explained above, further increases $\left(T_{s 2}-T_{s 1}\right)_{\max }$ (Fig. 2a).

Increasing $F_{s}$, which destabilizes the atmosphere to convection, allows the convecting solution to exist at lower $\varepsilon_{0}$ (i.e., decreases $\varepsilon_{c}$; Fig. $\left.3 \mathrm{~b}\right)$; however, $\left(T_{s 2}-\right.$
$\left.T_{s 1}\right)_{\max }$ increases slightly as $F_{s}$ increases (Fig. 2b) instead of decreasing as one might expect from the decrease in $\varepsilon_{c}$. This is because the surface and atmosphere are more tightly coupled in the convecting solution, so more of the heating resulting from increasing $F_{s}$ goes into increasing the surface temperature in the nonconvecting solution than in the convecting solution.

Increasing $F_{a}$ increases the surface temperature more in the convecting solution than in the nonconvecting solution, which increases $\left(T_{s 2}-T_{s 1}\right)_{\max }$ (Fig. 2c), because the surface and atmosphere are more tightly coupled in the convecting solution. The warming effect of $F_{a}$ tends to destabilize the atmosphere to convection, but this effect is dominated by the direct stabilizing effect of $F_{a}$ so that $\varepsilon_{c}$ increases with $F_{a}$ (Fig. 3c). This increase in $\varepsilon_{c}$ as $F_{a}$ increases helps to explain why the increase in $\left(T_{s 2}-T_{s 1}\right)_{\max }$ with $F_{a}$ is so small.

Increasing $P_{a}$ has no effect on the nonconvecting solution. It does cause a large decrease in $\varepsilon_{c}$ (Fig. 3d) 
(a)
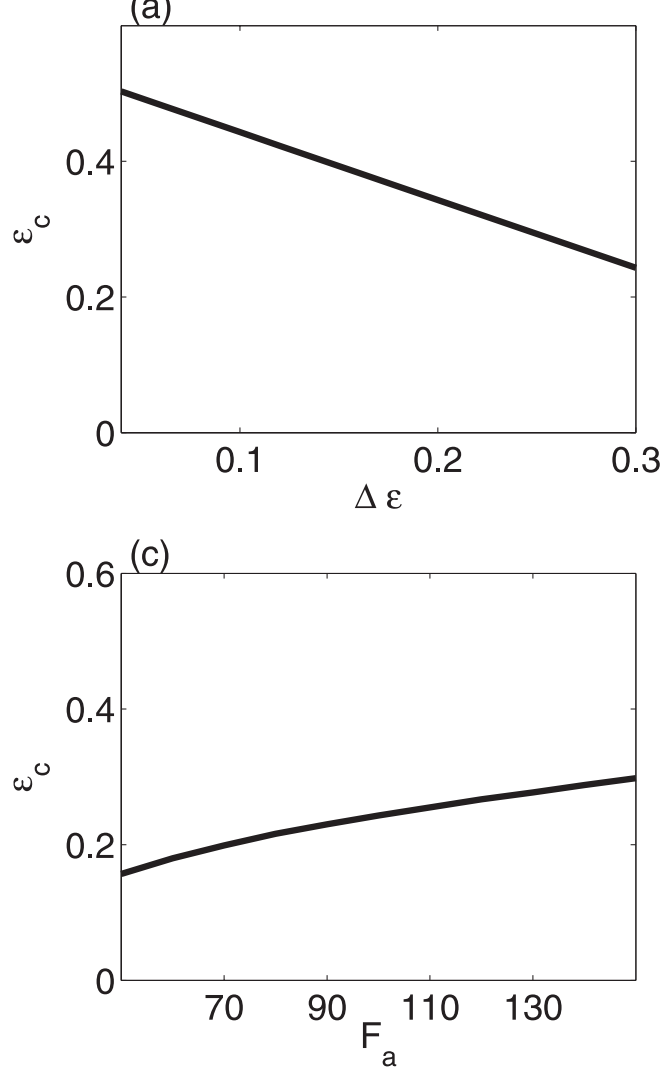

(b)

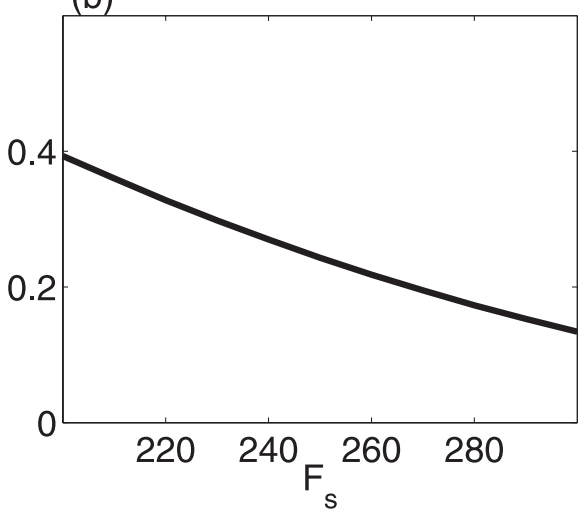

(d)

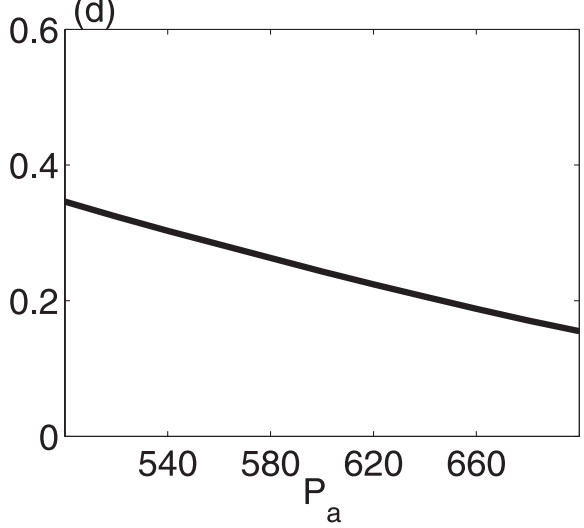

FIG. 3. As in Fig. 2, but for $\varepsilon_{c}$, the smallest emissivity at which the convective solution exists.

because it is easier to reach the moist convective criticality if the height of convection is lower [the gravitational term in (9) is smaller]. Decreasing the height of convection also means that $T_{a 2}$ is closer to $T_{s 2}$, so that the atmosphere provides less radiative forcing, and $\left(T_{s 2}-T_{s 1}\right)_{\max }$ decreases somewhat as $P_{a}$ is increased. This effect is relatively large at any particular value of $\varepsilon_{0}$, but the effect on the maximum temperature difference is muted by the fact that $\varepsilon_{c}$ also decreases as $P_{a}$ is increased.

\section{SCAM}

We next analyze SCAM to determine whether the insight provided by the simple analytical model regarding the critical $\mathrm{CO}_{2}$ needed for the warm convecting state to exist $\left(\varepsilon_{c}\right)$ and the maximum strength of the convective cloud feedback $\left[\left(T_{s 2}-T_{s 1}\right)_{\max }\right]$ is valid in a more quantitative model. As in section 2, we are interested in investigating the convective cloud feedback in SCAM at high latitudes and during winter. Consequently, we run SCAM to steady state in simulated polar night (zero solar forcing, $S=0$ ). The real Arctic
Ocean is not in steady state during polar night: it radiates heat to space throughout polar night and continually cools. We have, however, already shown that the convective cloud feedback can function in the presence of a seasonal cycle (AT08b; AWT) and, as our objective here is to understand the feedback in depth, we feel justified in using the steady-state assumption, which greatly simplifies our analysis. In addition, in an ice-free Arctic Ocean, the surface heat capacity would be very high, so the approximation of considering the steady-state solution should be reasonable. To obtain an above-freezing equilibrated surface temperature at realistic atmospheric heat transport values, we need to specify a nonzero net surface heat flux (NSHF) from the surface to the atmosphere. The NSHF represents a combination of the convergence of ocean heat transport and the winter release of heat that the ocean stored during the summer.

We couple SCAM to a mixed layer ocean of depth $50 \mathrm{~m}$, set the surface wind velocity to a constant $5 \mathrm{~m} \mathrm{~s}^{-1}$ and set the vertical velocity to zero at all vertical levels. We run SCAM with ozone and sea salt aerosol set to their annual mean values at a latitude of $79.5^{\circ} \mathrm{N}$ and a 
longitude of $143.4^{\circ} \mathrm{W}$, which is over the Arctic Ocean. We set all other aerosol concentrations to zero. All boundary conditions that we apply to SCAM are time invariant. We apply the AHT to the atmosphere as dry transport equally by mass below $200 \mathrm{hPa}$, with the AHT going to zero smoothly as a hyperbolic tangent with a vertical thickness of $50 \mathrm{hPa}$. This means that, other than the smoothing near $200 \mathrm{hPa}$, the applied temperature tendency is the same for each pressure level below 200 $\mathrm{hPa}$. In a related study, AT08b found that the apportionment of AHT between dry and moist transport did not qualitatively affect their results.

When we run SCAM with zero solar forcing $(S=0)$ and large enough AHT and NSHF values, we find multiple equilibria, with a stable warm and convecting state possibly relevant to both future greenhouse warming and past equable climates, over a wide range of $\mathrm{CO}_{2}$ values (e.g., Figs. 4 and 5). In Fig. 4 we show the surface temperature of the warm and cold states with a realistic polar AHT of $100 \mathrm{~W} \mathrm{~m}^{-2}$ and different NSHF values, whereas in Fig. 5 we show that both states exist even when we drastically change the distribution of heat transports to NSHF $=170 \mathrm{~W} \mathrm{~m}^{-2}$ and $\mathrm{AHT}=0 \mathrm{~W} \mathrm{~m}^{-2}$. The solution of SCAM (Figs. 4 and 5) as a function of $\log \left(\mathrm{CO}_{2}\right)$ looks similar to that of the two-level model (Fig. 1) as a function $\varepsilon_{0}$. There is a wide range in $\log \left(\mathrm{CO}_{2}\right)$ over which both the warm and cold solutions exist and, particularly in Fig. 5, the surface temperature of the cold state increases faster with $\mathrm{CO}_{2}$ than the surface temperature of the warm state. The cold state sea surface temperature sometimes reaches the freezing point of seawater, $-1.8^{\circ} \mathrm{C}$ (Fig. 4 ), in which case we hold the sea surface temperature at this value. This represents an extra artificial heat flux from the surface into the atmosphere, in addition to the applied NSHF; however, even with this extra heat flux the cold state is still stable. Such cold states would approach the ice states of AT08b if allowed to fully equilibrate in a model that included sea ice.

The warm equilibrium is significantly warmer than the cold equilibrium when both states exist. For example, with $\mathrm{CO}_{2}=2000 \mathrm{ppm}$, AHT $=100 \mathrm{~W} \mathrm{~m}^{-2}$, and $\mathrm{NSHF}=70 \mathrm{~W} \mathrm{~m}^{-2}$, the surface temperature is $7.0^{\circ} \mathrm{C}$ in the warm state and $-1.8^{\circ} \mathrm{C}$ in the cold state (it is prescribed not to go below the freezing temperature of seawater, as described above). The convective cloud feedback is the major cause of this difference, as the cloud radiative forcing in the warm state $\left(45.7 \mathrm{~W} \mathrm{~m}^{-2}\right)$ is nearly double that in the cold state $\left(25.6 \mathrm{~W} \mathrm{~m}^{-2}\right)$. The change in cloud radiative forcing is due to more and thicker high clouds in the warm state (Figs. 6c,d). These clouds result from stronger and deeper convection (Figs. 6g,h), which leads to increased midtropospheric
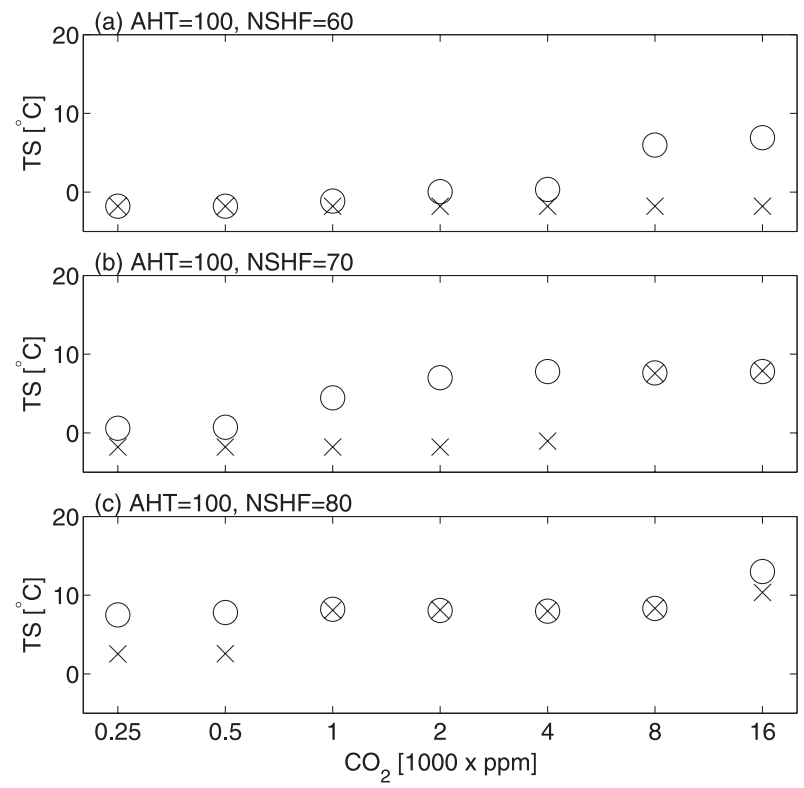

FIG. 4. Equilibrated surface temperature (TS) of the warm (circles) and cold (crosses) states in SCAM at different $\mathrm{CO}_{2}$ levels with zero solar radiation $\left(S=0 \mathrm{~W} \mathrm{~m}^{-2}\right)$, an atmospheric heat transport (AHT) of $100 \mathrm{~W} \mathrm{~m}^{-2}$, and a net surface heat flux (NSHF) of (a) 60, (b) 70, and (c) $80 \mathrm{~W} \mathrm{~m}^{-2}$.

ice condensate (Fig. 6f) and increased cloud fraction (Fig. 6c).

SCAM calculates the depth of convection, thickness of clouds, and amount of moisture. Therefore, in SCAM there are no analogs to $P_{a}$ and $\Delta \varepsilon$ from the two-level model for us to vary; however, we can investigate the effect of changing the NSHF (an analog of $F_{s}$ in the twolevel model) and the AHT (an analog of $F_{a}$, with a complication to be explained) on the convective cloud feedback in SCAM. The lowest $\mathrm{CO}_{2}$ at which the warm

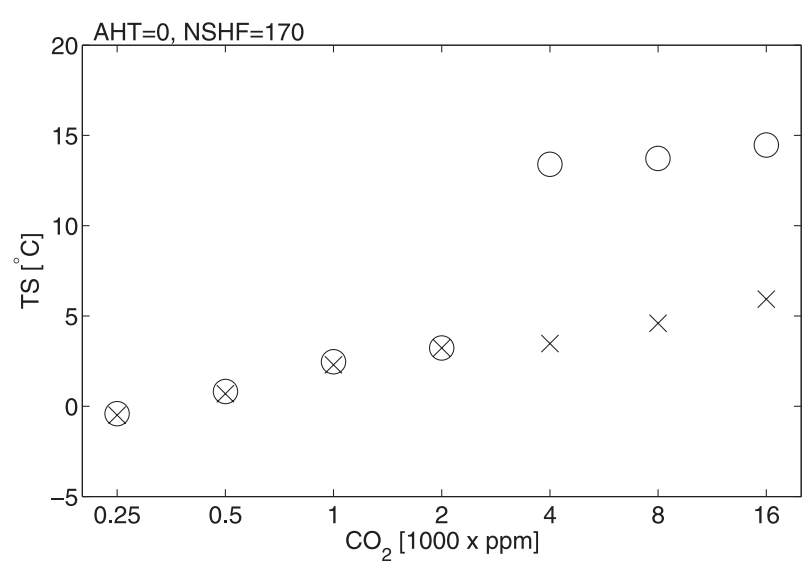

FIG. 5. As in Fig. 4, but with AHT $=0 \mathrm{~W} \mathrm{~m}^{-2}$ and $\mathrm{NSHF}=170 \mathrm{~W} \mathrm{~m}^{-2}$. 
(a) Air Temp. [K]

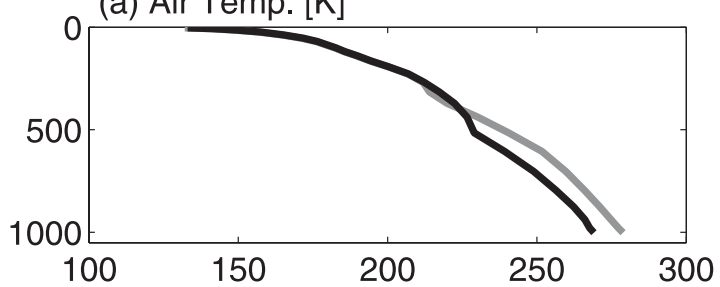

(c) Cloud Fraction [0-1]

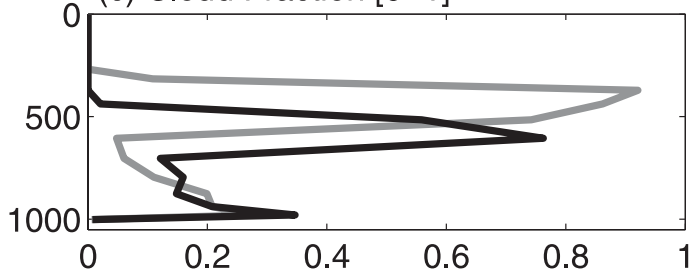

(e) Liquid Condensate $\left[10^{-5} \mathrm{~kg} \mathrm{~kg}^{-1}\right]$

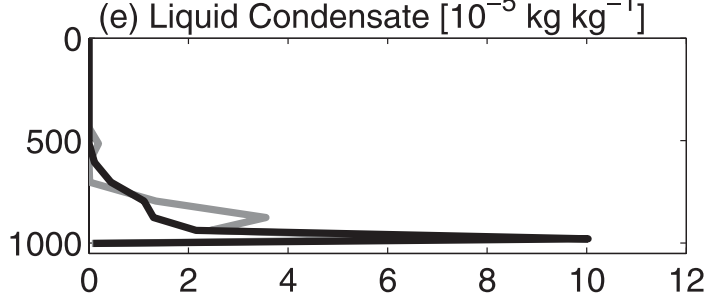

(g) Moist Conv. Mass Flux $\left[\mathrm{kg} \mathrm{m}^{-2} \mathrm{~s}^{-1}\right]$

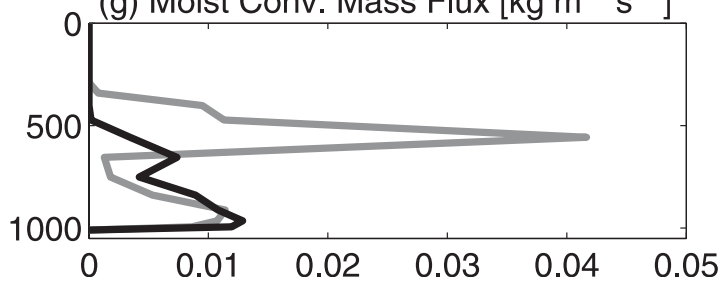

(b) Air Temp. Difference [K]

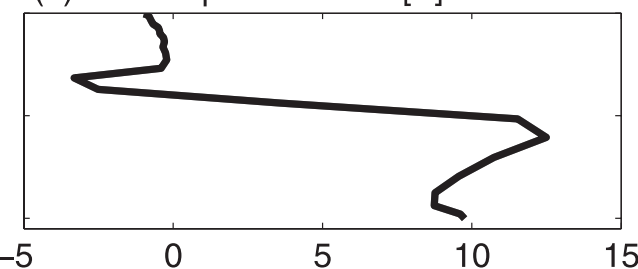

(d) Effective Cloud Fraction [0-1]
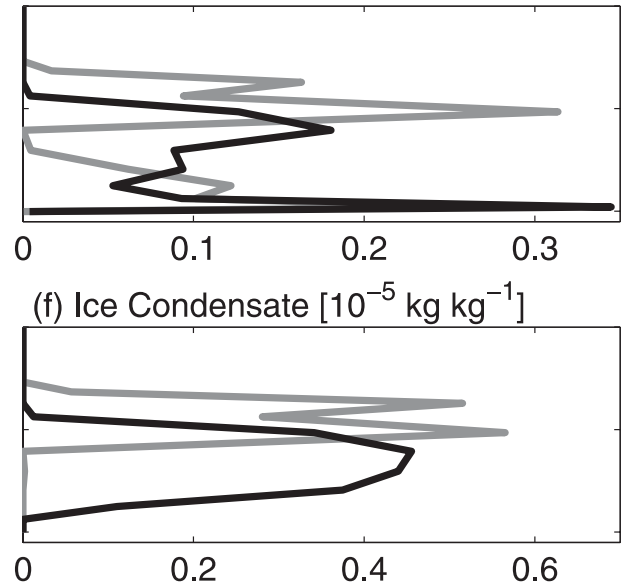

(h) Conv. Cld. Frac [0-1]

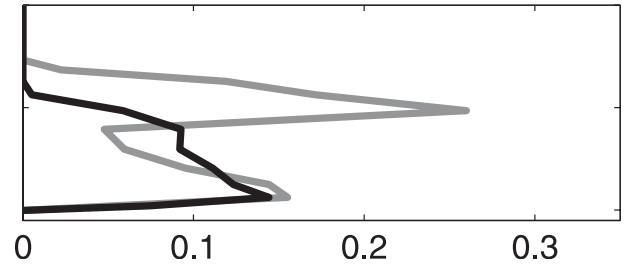

FIG. 6. Vertical profiles of important SCAM output with zero solar radiation $\left(S=0 \mathrm{~W} \mathrm{~m}^{-2}\right), \mathrm{AHT}=100 \mathrm{~W} \mathrm{~m}^{-2}$, $\mathrm{NSHF}=70 \mathrm{~W} \mathrm{~m}^{-2}$, and $\mathrm{CO}_{2}=2000 \mathrm{ppm}$ for the warm (gray) and cold (black) states. The effective cloud fraction is the product of the cloud fraction and the cloud emissivity for each layer. The convective cloud fraction is the cloud fraction produced by the convection scheme. The total cloud fraction in a region with convection is often higher than the convective cloud fraction because the model often produces stratiform clouds in these regions as well.

state exists (critical $\mathrm{CO}_{2}$ is an analog of $\varepsilon_{c}$ in the twolevel model), one of the most important variables investigated in this paper, decreases sharply as the NSHF is increased (Table 1), which is consistent with the strong decrease of $\varepsilon_{c}$ as $F_{s}$ increases in the two-level model (Fig. 3b). For AHT values comparable to modern Arctic values, the critical $\mathrm{CO}_{2}$ spans the entire plausible $\mathrm{CO}_{2}$ range for the early Paleogene $(\sim 250-\sim 4000 \mathrm{ppm}$; Pagani et al. 2005; Pearson and Palmer 2000) when the NSHF is changed by $20 \mathrm{~W} \mathrm{~m}^{-2}$ (Table 1 ). This underscores the importance of the absorption of summer solar radiation for the maintenance of the warm state.

The critical $\mathrm{CO}_{2}$ in SCAM also decreases sharply as the AHT is increased, which appears to contradict the increase in $\varepsilon_{c}$ as $F_{a}$ increases in the two-level model (Fig. 3c). The main reason for this is that because the
AHT in SCAM is applied equally throughout the troposphere, it is not a direct analog for $F_{a}$ from the twolevel model but should actually be thought of as some combination of $F_{s}$ and $F_{a}$. Furthermore, an AHT applied in this way does not directly change the stability, so its main effect is to warm the model, which decreases the critical $\mathrm{CO}_{2}$. We should note that the formulation of the vertical distribution of AHT in SCAM we have used is not necessarily realistic; for example, we have not taken into account reduced near-surface AHT due to surface friction (e.g., Branscome et al. 1989; Stone and Yao 1990). The main lesson we should learn from these SCAM runs and the two-level model is that the effect of the AHT on the critical $\mathrm{CO}_{2}$ depends strongly on the detailed vertical distribution of AHT. 
TABLE 1. The critical $\mathrm{CO}_{2}$ concentration (ppm), the lowest $\mathrm{CO}_{2}$ concentration at which the warm state can exist (the convective cloud feedback can be active), in SCAM as a function of the prescribed AHT and NSHF. We ran SCAM at every doubling of $\mathrm{CO}_{2}$ concentration between 250 and 16000 ppm, as in Figs. 4 and 5. The warm state does not exist at any $\mathrm{CO}_{2}$ concentration below $16000 \mathrm{ppm}$ for AHT $=90 \mathrm{~W} \mathrm{~m}^{-2}$ and $\mathrm{NSHF}=60$ and $70 \mathrm{~W} \mathrm{~m}^{-2}$.

\begin{tabular}{lccc}
\hline & $\begin{array}{c}\text { NSHF }=60 \\
\mathrm{~W} \mathrm{~m}^{-2}\end{array}$ & $\begin{array}{c}\text { NSHF }=70 \\
\mathrm{~W} \mathrm{~m}^{-2}\end{array}$ & $\begin{array}{c}\text { NSHF }=80 \\
\mathrm{~W} \mathrm{~m}^{-2}\end{array}$ \\
\hline AHT $=90 \mathrm{~W} \mathrm{~m}^{-2}$ & - & - & 2000 \\
AHT $=100 \mathrm{~W} \mathrm{~m}^{-2}$ & 8000 & 1000 & 250 \\
AHT $=110 \mathrm{~W} \mathrm{~m}^{-2}$ & 250 & 250 & 250 \\
\hline
\end{tabular}

There is no discernible pattern in the change in the maximum surface temperature difference between the warm and cold states as AHT and NSHF are varied (Table 2). This is consistent with the relatively small changes in $\left(T_{s 2}-T_{s 1}\right)_{\max }$ as $F_{s}$ and $F_{a}$ are varied in the two-level model (section 2b). Additionally, because of the high sensitivity of the critical $\mathrm{CO}_{2}$ to NSHF, we only vary AHT and NSHF over relatively small ranges compared to the ranges over which we varied $F_{s}$ and $F_{a}$ in the two-level model.

\section{Discussion}

Results from the two-level model (section 2) helped us motivate and understand results from SCAM (section 3). For example, both models agree that the critical $\mathrm{CO}_{2}$ at which the convective cloud feedback activates is sharply dependent on surface heat flux. To the extent that the surface heat flux in these models can be interpreted as the winter release of heat stored by the ocean during the summer, this suggests that more clouds during summer, which reflect solar radiation and therefore reduce the amount of solar radiation absorbed by the surface, should lead to a higher critical $\mathrm{CO}_{2}$. The use of both models in conjunction with each other also helped us understand that the vertical distribution of the atmospheric heat transport is at least as important as its magnitude for determining the critical $\mathrm{CO}_{2}$. This represents an important limitation on our ability to predict the critical $\mathrm{CO}_{2}$ because currently even the magnitude of the atmospheric heat transport during equable climates-resulting from a competition between reduced dry static energy transport (due to reduced meridional temperature gradient) and increased latent energy transport (due to increased subtropical temperature and moisture) —is unknown (Pierrehumbert 2002; Caballero and Langen 2005).

The two-level model, however, is useful beyond its relation to SCAM. SCAM interactively predicts the depth of convection, thickness of clouds, and amount of
TABLE 2. The maximum temperature difference $\left({ }^{\circ} \mathrm{C}\right)$ between the warm and cold states in SCAM as a function of the prescribed AHT and NSHF. We ran SCAM at every doubling of $\mathrm{CO}_{2}$ concentration between 250 and 16000 ppm, as in Figs. 4 and 5. The warm state does not exist at any $\mathrm{CO}_{2}$ concentration below $16000 \mathrm{ppm}$ for $\mathrm{AHT}=90 \mathrm{~W} \mathrm{~m}^{-2}$ and $\mathrm{NSHF}=60$ and $70 \mathrm{Wm}^{-2}$.

\begin{tabular}{lccc}
\hline \hline & $\begin{array}{c}\mathrm{NSHF}=50 \\
\mathrm{~W} \mathrm{~m}^{-2}\end{array}$ & $\begin{array}{c}\mathrm{NSHF}=60 \\
\mathrm{~W} \mathrm{~m}^{-2}\end{array}$ & $\begin{array}{c}\mathrm{NSHF}=70 \\
\mathrm{~W} \mathrm{~m}^{-2}\end{array}$ \\
\hline $\mathrm{AHT}=90 \mathrm{~W} \mathrm{~m}^{-2}$ & - & - & 3.5 \\
$\mathrm{AHT}=100 \mathrm{~W} \mathrm{~m}^{-2}$ & 8.7 & 8.8 & 5.2 \\
$\mathrm{AHT}=110 \mathrm{~W} \mathrm{~m}^{-2}$ & 9.8 & 10.2 & 3.5 \\
\hline
\end{tabular}

moisture, whereas in the two-level model we are able to vary these at will through the parameters $\Delta \varepsilon$ and $P_{a}$ to understand their effect on the convective cloud feedback. The main interesting and unexpected results from the two-level model are that increasing the height of convection significantly increases the critical $\mathrm{CO}_{2}$ and that increasing the height of convection has very little effect on the maximum surface temperature difference between the cold and warm state, although it does significantly increase the convecting solution surface temperature and therefore the surface temperature difference at any particular $\varepsilon_{0}\left(\mathrm{CO}_{2}\right)$.

This type of understanding, gained from the two-level model, could be quite useful for interpretation of general circulation model (GCM) results. For example, AWT found that the convective cloud feedback increased the uncertainty in winter sea ice forecasts in the coupled ocean-sea ice-land-atmosphere GCMs that participated in the IPCC fourth assessment report for the scenario in which a $1 \%$ year ${ }^{-1} \mathrm{CO}_{2}$ increase was quadrupled. The extent to which sea ice was lost and the feedback was active are related to the critical $\mathrm{CO}_{2}$; perhaps insight from the two-level model could help us understand the differences between these models.

Two of the GCMs that participated in the IPCC $\mathrm{CO}_{2}$ quadrupling scenario completely lost winter sea ice at the end of the experiment. The Arctic winter sea surface temperature in these models was barely above freezing, and the cloud radiative forcing was about $30 \mathrm{~W} \mathrm{~m}^{-2}$ which, though significant, is much smaller than the roughly $50 \mathrm{~W} \mathrm{~m}^{-2}$ found in SCAM in this paper and by AT08b when the surface temperature was $10^{\circ}-15^{\circ} \mathrm{C}$ higher. This difference in cloud radiative forcing occurred mainly because the convection was shallower in the ice-free GCMs (reaching about $800 \mathrm{hPa}$ ) than in SCAM (reaching 400-500 hPa). AWT speculated that the GCMs might have produced deeper convection and a stronger feedback if the $\mathrm{CO}_{2}$ was further increased or the run was integrated until it was closer to equilibrium. This paper raises the possibility that the convective 
cloud feedback operating in the atmosphere alone could introduce sufficient nonlinearity to allow a hysteresis such that if the GCMs were started from much warmer ice-free conditions, instead of ice-covered conditions, they might have equilibrated with deeper convection and a higher surface temperature like SCAM did.

Renno (1997) and Sobel et al. (2007) have found multiple equilibria in single-column atmospheric models that include representations of the hydrological cycle. The Renno (1997) study does not include clouds, so it is quite different from this study. The work of Sobel et al. (2007) is more similar to this study in that they find two separate steady states, one convecting and one not convecting; however, by using the weak temperature gradient assumption, they focus on the tropics, and their model uses fixed surface temperatures rather than prognostic surface temperatures in an energy-conserving model. The convecting and nonconvecting states of Sobel et al. (2007) are not "warm" and "cold" because both are forced at the same surface temperature; rather, they are "wet" and "dry."

In the two-level model of section 2, we assumed that the atmospheric emissivity increased by a constant offset $(\Delta \varepsilon)$ upon the onset of convection. One might alternatively suspect that the radiative effect of convective clouds might increase with the strength of convection. This is the case in the warm SCAM states of Fig. 4: the cloud radiative forcing increases roughly linearly with the maximum convective mass flux in the midtroposphere (not shown). When we modify the two-level model so that the emissivity increases linearly with the convective heat flux $F_{c}$ instead of all at once when convection starts, we find that the model still exhibits hysteresis and our main conclusions are unaltered.

The convective cloud feedback could help to keep the Arctic Ocean ice free throughout the winter. This would likely lead to a situation with relatively warm ocean surrounded by relatively cold continent. This could lead to a low pressure system over the ocean and possibly, even though the Coriolis parameter would be large and the Ekman number small, to Ekman pumping, inflow at low levels, and vertical ascent. In this paper, we have specified the vertical velocity to be zero at every level (section 3), so we have neglected such an effect; however, it seems likely that such upward motion would augment the convective activity over the ocean.

The two-level model we used in this study is intentionally quite simple; and SCAM, although it has sophisticated cloud, convection, and radiation schemes, lacks dynamics. In both models we need to specify horizontal heat transports, which define the models' interaction with surrounding areas, and prescribe a net surface heat flux to simulate seasonal heat storage. In one sense, the simplicity of these models is a limitation of this study; however, the convective cloud feedback has been shown to be active in state-of-the-art coupled GCMs (AWT), and here we have used the two simple models in conjunction to gain a deeper understanding of the feedback.

A major part of the equable climate mystery is warmth during the winter in continental interiors (e.g., Greenwood and Wing 1995). Implicitly, this paper has focused on polar night over oceans because we have net heat flux from the surface into the atmosphere, which would have to come from either ocean heat transport or the storage of heat during the summer by the ocean and release during the winter. We are currently investigating the role the convective cloud feedback could play in warming continental interiors.

\section{Conclusions}

In this paper we used a simple two-level model of the atmosphere and ocean and NCAR's single-column atmospheric model coupled to a mixed layer ocean to analyze the critical $\mathrm{CO}_{2}$ concentration at which a highlatitude convective cloud feedback can become active and the strength of this high-latitude convective cloud feedback, as measured by its ability to raise the surface temperature. The critical $\mathrm{CO}_{2}$ is particularly important because it determines whether the convective cloud feedback could have been active during periods of equable climate and in a future climate, because understanding what controls it may aide in understanding why the convective cloud feedback is more active in some GCMs than in others at the same $\mathrm{CO}_{2}$ concentration, and because it has a large effect on the overall strength of the feedback (section 2b). Our main findings follow:

- If the feedback produces more and thicker convective clouds, it should activate at a lower $\mathrm{CO}_{2}$ and be stronger.

- If the feedback produces deeper convection, it should activate at a higher $\mathrm{CO}_{2}$, be much stronger at any particular $\mathrm{CO}_{2}$, and have a somewhat larger maximum strength.

- If the net heat released by the surface during winter, produced either by ocean heat transport or by the release of seasonally stored heat, increases, the critical $\mathrm{CO}_{2}$ should decrease sharply and the strength of the feedback should not change much.

- The effects of atmospheric heat transport are complicated and depend on the detailed vertical structure of this heat transport. 
Acknowledgments. We thank Bill Boos and Chris Walker for helpful conversations and two anonymous reviewers for their comments. DA is supported by an NSF graduate research fellowship. This work is funded by the NSF paleoclimate program, ATM0455470, and the McDonnell Foundation. ET thanks the Weizmann Institute for its hospitality during parts of this work.

\section{REFERENCES}

Abbot, D. S., and E. Tziperman, 2008a: A high-latitude convective cloud feedback and equable climates. Quart. J. Roy. Meteor. Soc., 134, 165-185, doi:10.1002/qj.211.

$\longrightarrow$, and — 2008b: Sea ice, high-latitude convection, and equable climates. Geophys. Res. Lett., 35, L03702, doi:10.1029/ 2007GL032286.

Baker, M. B., 1997: Cloud microphysics and climate. Science, 276, $1072-1078$

Branscome, L. E., W. J. Gutowski, and D. A. Stewart, 1989: Effect of surface fluxes on the nonlinear development of baroclinic waves. J. Atmos. Sci., 46, 460-475.

Caballero, R., and P. L. Langen, 2005: The dynamic range of poleward energy transport in an atmospheric general circulation model. Geophys. Res. Lett., 32, L02705, doi:10.1029/ 2004 GL021581.

Cess, R. D., and Coauthors, 1990: Intercomparison and interpretation of cloud-climate feedback processes in 19 atmospheric general circulation models. J. Geophys. Res., 95, 16 601-16 615.

_- and Coauthors, 1996: Cloud feedback in atmospheric general circulation models: An update. J. Geophys. Res., 101, $12791-$ 12794.

Emanuel, K., 2002: A simple model of multiple climate regimes. J. Geophys. Res., 107, 4077, doi:10.1029/2001JD001002.

Farrell, B. F., 1990: Equable climate dynamics. J. Atmos. Sci., 47, 2986-2995.

Greenwood, D. R., and S. L. Wing, 1995: Eocene continental climates and latitudinal temperature gradients. Geology, 23, 1044-1048.

Huber, M., and L. C. Sloan, 1999: Warm climate transitions: A general circulation modeling study of the Late Paleocene Thermal Maximum ( 56 Ma). J. Geophys. Res., 104, 16 633-16 655.

Kirk-Davidoff, D. B., D. P. Schrag, and J. G. Anderson, 2002: On the feedback of stratospheric clouds on polar climate. Geophys. Res. Lett., 29, 1556, doi:10.1029/2002GL014659.

Korty, R. L., K. A. Emanuel, and J. R. Scott, 2008: Tropical cyclone-induced upper-ocean mixing and climate: Application to equable climates. J. Climate, 21, 638-654.

Murphy, J. M., D. M. H. Sexton, D. N. Barnett, G. S. Jones, M. J. Webb, M. Collins, and D. A. Stainforth, 2004: Quantification of modelling uncertainties in a large ensemble of climate change simulations. Nature, 430, 768-772.

Norris, R. D., K. L. Bice, E. A. Magno, and P. A. Wilson, 2002 Jiggling the tropical thermostat in the Cretaceous hothouse. Geology, 30, 299-302.

Pagani, M., J. C. Zachos, K. H. Freeman, B. Tipple, and S. Bohaty, 2005: Marked decline in atmospheric carbon dioxide concentrations during the Paleogene. Science, 309, 600-603.
Pearson, P. N., and M. R. Palmer, 2000: Atmospheric carbon dioxide concentrations over the past 60 million years. Nature, 406, 695-699.

, P. W. Ditchfield, J. Singano, K. G. Harcourt-Brown, C. J. Nicholas, R. K. Olsson, N. J. Shackleton, and M. A. Hall, 2001: Warm tropical sea surface temperatures in the Late Cretaceous and Eocene epochs. Nature, 413, 481-487.

Peters, R. B., and L. C. Sloan, 2000: High concentrations of greenhouse gases and polar stratospheric clouds: A possible solution to high-latitude faunal migration at the latest $\mathrm{Pa}$ leocene thermal maximum. Geology, 28, 979-982.

Pierrehumbert, R. T., 2002: The hydrologic cycle in deep time climate problems. Nature, 419, 191-198.

Renno, N. O., 1997: Multiple equilibria in radiative-convective atmospheres. Tellus, 49A, 423-438.

Roche, D. M., Y. Donnadieu, E. Pucéat, and D. Paillard, 2006: Effect of changes in $\delta^{18} \mathrm{O}$ content of the surface ocean on estimated sea surface temperatures in past warm climate. Paleoceanography, 21, PA2023, doi:10.1029/2005PA001220.

Sasamori, T., 1968: The radiative cooling calculation for application to general circulation experiments. J. Appl. Meteor., 7, 721-729.

Sloan, L. C., and D. Pollard, 1998: Polar stratospheric clouds: A high latitude warming mechanism in an ancient greenhouse world. Geophys. Res. Lett., 25 (18), 3517-3520.

_ , J. C. G. Walker, T. C. Moore, D. K. Rea, and J. C. Zachos, 1992: Possible methane-induced polar warming in the early Eocene. Nature, 357, 320-322.

_ M. Huber, and A. Ewing, 1999: Polar stratospheric cloud forcing in a greenhouse world: A climate modeling sensitivity study. Reconstructing Ocean History: A Window into the Future, F. Abrantes and A. Mix, Eds., Springer, 273-293.

Sluijs, A., and Coauthors, 2006: Subtropical Arctic ocean temperatures during the Palaeocene/Eocene thermal maximum. Nature, 441, 610-613.

Sobel, A. H., G. Bellon, and J. Bacmeister, 2007: Multiple equilibria in a single-column model of the tropical atmosphere. Geophys. Res. Lett., 34, L22804, doi:10.1029/2007GL031320.

Soden, B. J., and I. M. Held, 2006: An assessment of climate feedbacks in coupled ocean-atmosphere models. J. Climate, 19, 3354-3360.

Stainforth, D. A., and Coauthors, 2005: Uncertainty in predictions of the climate response to rising levels of greenhouse gases. Nature, 433, 403-406.

Stone, P. H., and M.-S. Yao, 1990: Development of a twodimensional zonally averaged statistical dynamical model. Part III: The parameterization of the eddy fluxes of heat and moisture. J. Climate, 3, 726-740.

Trenberth, K. E., and D. P. Stepaniak, 2003: Covariability of components of poleward atmospheric energy transports on seasonal and interannual timescales. J. Climate, 16, 36913705 .

Tripati, A. K., M. L. Delaney, J. C. Zachos, L. D. Anderson, D. C. Kelly, and H. Elderfield, 2003: Tropical sea surface temperature reconstruction for the early Paleogene using $\mathrm{Mg} / \mathrm{Ca}$ ratios of planktonic foraminifera. Paleoceanography, 18,1101, doi:10.1029/2003PA000937.

Zachos, J., M. Pagani, L. Sloan, E. Thomas, and K. Billups, 2001: Trends, rhythms, and aberrations in global climate $65 \mathrm{Ma}$ to present. Science, 292, 686-693. 